\title{
Outcomes after mitral valve surgery for rheumatic heart disease
}

\author{
E Anne Russell, ${ }^{1,2}$ Warren F Walsh, ${ }^{3}$ Christopher M Reid, ${ }^{2,4}$ Lavinia Tran, ${ }^{2}$ Alex Brown, ${ }^{5,6}$ \\ Jayme S Bennetts, ${ }^{7,8}$ Robert A Baker, ${ }^{7}$ Robert Tam, ${ }^{9}$ Graeme P Maguire ${ }^{1,2}$
}

- Additional material is published online only. To view please visit the journal online (http://dx.doi.org/10.1136/ heartasia-2017-010916)

${ }^{1}$ Clinical Research Domain, Baker Heart and Diabetes Institute, Melbourne, Victoria, Australia

${ }^{2}$ School of Epidemiology and Preventive Medicine, Monash University, Melbourne, Victoria, Australia

${ }^{3}$ Department of Cardiology, Prince of Wales Hospital, Randwick, NSW, Australia

${ }^{4}$ School of Public Health, Curtin University, Perth, WA, Australia ${ }^{5}$ Wardliparingga Aboriginal Research Unit, South Australia Health and Medical Research Institute, Adelaide, Australia ${ }^{6}$ School of Population Health, University of South Australia, Adelaide, South Australia ${ }^{7}$ Department of Cardiac and Thoracic Surgery, Flinders Medical Centre, Adelaide, Australia

${ }^{8}$ Department of Surgery, School of Medicine, Flinders University, Adelaide, South Australia,

Australia

${ }^{9}$ Department of Cardiothoracic Surgery, The Townsville Hospital, Townsville, Queensland, Australia

\section{Correspondence to} Professor Graeme P Maguire, Baker IDI Heart and Diabetes Institute, Melbourne, Victoria 3004, Australia ; graeme. maguire@bakeridi.edu.au

Received 12 April 2017 Revised 3 May 2017

Accepted 4 May 2017 Published Online First 23 May 2017

\section{CrossMark}

To cite: Russell EA, Walsh WF, Reid CM, et al. Heart Asia

2017:9:1-7.. doi:10.1136/ heartasia-2017-010916

\section{ABSTRACT}

Objective To further the understanding of the factors influencing outcome following rheumatic heart disease (RHD) related mitral valve surgery, which globally remains an important cause of heart disease and a particular problem in Indigenous Australians.

Methods The Australian Cardiac Surgery Database was utilised to assess outcomes following mitral valve repair and replacement for RHD and non-RHD valve disease. The association with aetiology, demographics, comorbidities, preoperative status and operative procedure was evaluated.

Results Mitral valve repairs and replacements undertaken in Australia were analysed from 119 and 1078 RHD surgical procedures and 3279 and 2400 nonRHD procedures, respectively. RHD mitral valve repair, compared with replacement, resulted in a slightly shorter hospital stay and more reoperation for valve dysfunction, but no difference in 30-day survival. In unadjusted survival analysis to 5 years, RHD mitral valve repair and replacement were no different (HR $0.86,95 \% \mathrm{Cl} 0.4$ to 1.7$)$, non-RHD repair was superior to replacement (HR 1.7, 95\% Cl 1.4 to 2.0), RHD and non-RHD repair were no different (HR $0.9,95 \% \mathrm{Cl} 0.5$ to 1.7 ), and RHD replacement was superior to non-RHD (HR 1.5, 95\% Cl 1.2 to 1.9). None of these differences persisted in adjusted analyses and there was no difference in longterm survival for Indigenous Australians.

Conclusion In this large prospective cohort study we have demonstrated that adjusted long-term survival following RHD mitral valve repair surgery in Australia is no different to replacement and no different to non-RHD. Interpretation of valve surgery outcome requires careful consideration of patient factors that may also influence survival.

\section{INTRODUCTION}

The most common heart valve affected by rheumatic heart disease (RHD) is the mitral valve. Management of advanced RHD involves one or a combination of medical management and surgical and non-surgical interventions, with surgical procedures being valve repair, open valvuloplasty or replacement. Replaced valves can be mechanical (entirely synthetic) or bioprosthetic (typically a combination of synthetic and animal or human derived material).

Despite its global impact there remains limited evidence to indicate the most appropriate timing and choice of intervention for RHD-related mitral valve disease. ${ }^{12}$

Factors that may influence the type of surgical management for RHD-related valve disease include age, gender and potential future pregnancies, adherence to other medications, availability of local primary and specialist follow-up and social circumstances, ${ }^{3-5}$ co-existent atrial fibrillation (where anticoagulation may be indicated irrespective of the procedure undertaken), the number of valves involved, preoperative left ventricular size and function, and co-existent pulmonary hypertension. ${ }^{4}$

RHD-related mitral valve repair has been associated with a reduced risk of complications from infection and anticoagulation compared with valve replacement ${ }^{6-8}$ and tends to be associated with superior overall short- and intermediate-term outcomes. ${ }^{8-10}$ However, not all valves are suitable for repair ${ }^{10}$ and repaired valves may be associated with an increased need for early reoperation. ${ }^{10}$ In part this relates to repaired valves remaining susceptible to further episodes of rheumatic fever and RHD progression. ${ }^{11}$

Despite evidence of superior outcome with mitral valve repair, we have previously reported ${ }^{12} 13$ that for RHD-related valve disease in Australia repairs are less commonly performed (5.3\% of all RHD-related valve procedures) compared with replacements (47.8\%). For Aboriginal Australian and Torres Strait Islander peoples (Indigenous Australians), a group of Australians at particular risk of RHD, of those valves requiring replacement or repair, $48.8 \%$ were mitral valve replacement and $13.4 \%$ mitral valve repair. ${ }^{12}$

The aim of this study was therefore to examine the Australian patient population that has had mitral valve surgery for RHD and non-RHD related valve disease and to describe short- and long-term outcome by analysing data from a large Australian multisite cardiac surgery registry. Given the greater burden of RHD-related valve disease in Indigenous Australians, who are also more likely to reside in remote locations, ${ }^{12}$ this study also aimed to examine specifically whether the management and outcome of RHD-related mitral valve disease was different in this particular group.

\section{METHODS}

\section{The database}

The Australia and New Zealand Society of Cardiac and Thoracic Surgeons (ANZSCTS) National Cardiac Surgery Database is an Australia-wide voluntary registry for the prospective collection and analysis of the results of adult cardiac surgery. The nature and breadth of this registry has been reported elsewhere. ${ }^{12}$ Briefly, it collects data from 25 Australian hospitals regarding patients who have undergone cardiac surgery, the types of surgery 


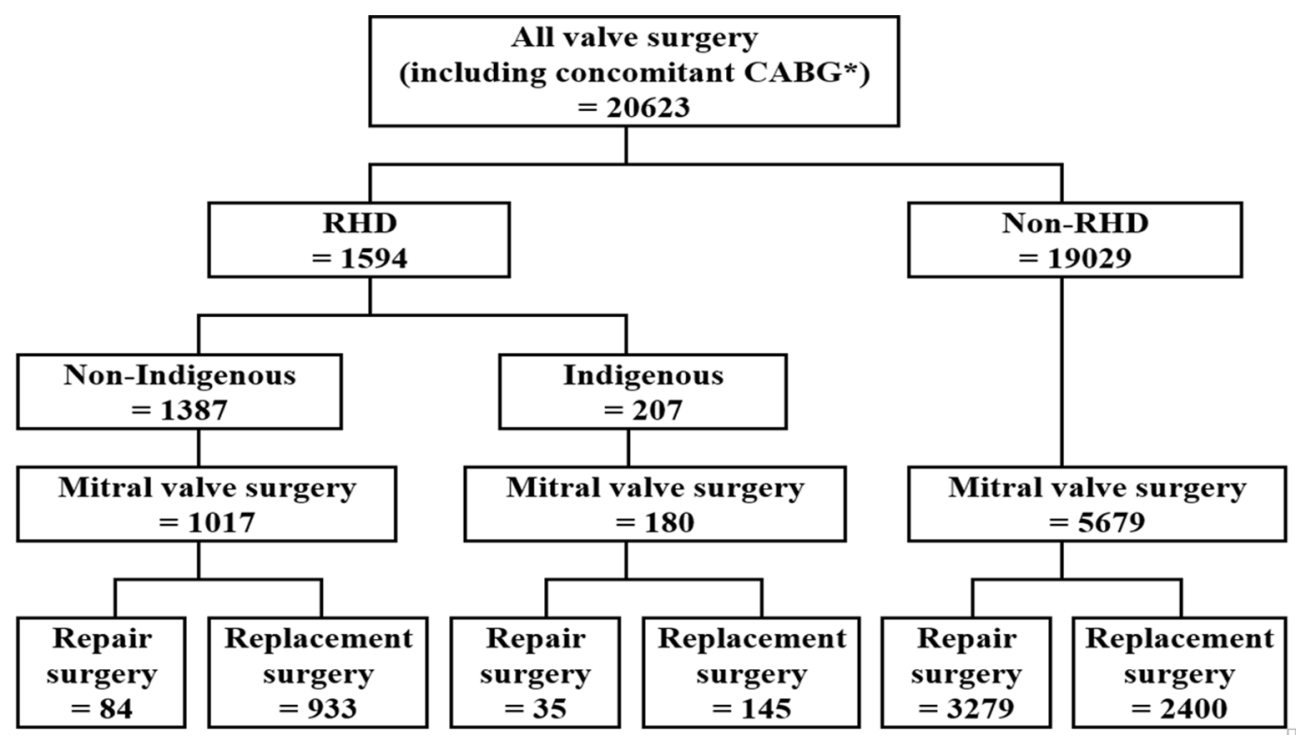

Figure 1 Flow diagram: rheumatic heart disease (RHD) and non-RHD related mitral valve procedures. CABG, coronary artery bypass grafting.

performed and early (30 day) complications, ${ }^{12} 1415$ and links this with long-term survival data.

\section{Selection criteria}

Participants were patients who had been registered on the database and who had undergone RHD or non-RHD-related mitral valve repair or replacement surgery with or without coronary artery bypass grafting (CABG) surgery.

\section{Analysis}

Data were analysed using IBM SPSS Statistics 20 (IBM, New York, USA) and STATA Release 14 (StataCorp LP, Texas, USA). Descriptive data (demographic, comorbidity data and surgery type) comparing RHD and non-RHD related mitral valve surgery type (repair or replacement) were summarised using standard univariate techniques and reported as percentages with 95\% CI, means with SD, or medians with IQR depending on the data format and distribution. Comparisons between groups were undertaken using $\chi^{2}$ for categorical data, Student's t-test and analysis of variance (ANOVA) for continuous normally distributed data, and Mann-Whitney $U$ and Kruskal-Wallis rank test for non-normally distributed data. A value of $\mathrm{p}<0.05$ was taken to indicate statistical significance and all tests were two-sided.

Early (<30 days) outcomes and complications included postoperative invasive ventilation time, number of hours spent in the intensive care unit (ICU), post-procedural length of stay, need for reoperation for valve or non-valve dysfunction, acute kidney injury, stroke or transient ischaemic attack (TIA), any anticoagulant complication (bleeding or embolisation), heart failure or septicaemia (positive blood culture with signs of infection), and readmission. Survival analysis encompassed 30-day mortality and longer-term survival was analysed out to 5 years.

The association between these outcomes and mitral valve surgery type (including when restricted to Indigenous Australians with RHD) was first assessed using standard bivariate techniques. Survival analysis for mortality was presented with Kaplan-Meier curves and analysed using the log rank test to compare survival in RHD and non-RHD mitral valve repair and replacement surgery, and then restricted to Indigenous and non-Indigenous Australians with RHD.

Multivariable logistic and Cox proportional hazard models were then developed to assess the independent association between surgery type and outcome measures controlling for demographic and comorbidity data where necessary. These models were developed using methods and predictors of survival identified from our previous studies. ${ }^{12} 1316$ Factors independently associated with long-term mortality following RHD valve surgery were age, diabetes, chronic kidney disease, prolonged ventilation time, and prolonged post-procedural length of hospital stay. This cohort study has been reported following the Strengthening the Reporting of Observational Studies in Epidemiology (STROBE) recommendations. ${ }^{17}$

Approval for this project was granted by the Monash University Human Research Ethics Committee (CF13/2737 2013001472).

\section{RESULTS}

Data in relation to 1197 RHD mitral valve surgical procedures including those of 180 Aboriginal and/or Torres Strait Islander people and 5679 non-RHD mitral valve procedures collated by the ANZCTS database between 1 June 2001 and 31 December 2013 were included for analysis (figure 1).

Demographic and comorbidity data relating to these patients are outlined in table 1. RHD-related mitral valve repair surgery was, compared with replacement surgery, more common in younger, male Indigenous patients with moderate or severe mitral valve regurgitation, and less common in those with concomitant preoperative comorbidities of chronic kidney disease, poorer preoperative performance, atrial fibrillation, mitral valve stenosis, and a history of smoking or previous intervention. In contrast, non-RHD mitral valve repair surgery compared with replacement surgery was significantly more common in female, non-Indigenous patients having concomitant CABG surgery and with normal left ventricular ejection fraction (LVEF).

\section{0-day outcomes}

Outcomes within 30 days of surgery comparing mitral valve repair and replacement for RHD and non-RHD valve disease are outlined in table 2 . In unadjusted analyses RHD mitral valve repair was associated with a slightly shorter length of hospital stay and a higher rate of reoperation for valve dysfunction. Patients having non-RHD mitral valve repair surgery, compared with replacement, had a shorter period of ventilation and stay 
Table 1 Descriptive characteristics of mitral valve surgery patients stratified by aetiology and surgery type

\begin{tabular}{|c|c|c|c|c|}
\hline & \multicolumn{2}{|l|}{ RHD } & \multicolumn{2}{|l|}{ Non-RHD } \\
\hline & $\begin{array}{l}\text { Repair surgery } \\
n=119\end{array}$ & $\begin{array}{l}\text { Replacement surgery } \\
\mathrm{n}=1078\end{array}$ & $\begin{array}{l}\text { Repair surgery } \\
\mathrm{n}=3279\end{array}$ & $\begin{array}{l}\text { Replacement surgery } \\
n=2400\end{array}$ \\
\hline Age (years) & 57.3 & $62.0^{*}$ & $67.0^{\dagger}$ & $69.3^{* \neq}$ \\
\hline (median, IQR) & (35.5 to 69.2 ) & (50.3 to 71.0$)$ & (57.6 to 75.2 ) & (58.3 to 77.0 ) \\
\hline Sex & 58.0 & $71.3^{*}$ & $30.3^{\dagger}$ & $38.3^{* \neq}$ \\
\hline (\% female, $95 \% \mathrm{Cl}$ ) & (48.6 to 67.0$)$ & (68.5 to 74.0$)$ & (28.7 to 31.9 ) & (36.4 to 40.3 ) \\
\hline Indigenous status & 29.4 & $13.5^{*}$ & $1.1^{\dagger}$ & $2.7^{*} \ddagger$ \\
\hline (\% Indigenous Australian, 95\% Cl) & (21.6 to 38.8 ) & (11.5 to 15.6$)$ & (0.8 to 1.6$)$ & (2.1 to 3.4 ) \\
\hline Concomitant CABG & 20.2 & 18.6 & $36.5^{\dagger}$ & $30.2^{* \ddagger}$ \\
\hline$(\%, 95 \% \mathrm{Cl})$ & (13.4 to 28.5$)$ & (16.4 to 21.1$)$ & (34.9 to 38.2 ) & (28.3 to 32.0 ) \\
\hline \multicolumn{5}{|l|}{ Preoperative comorbidities } \\
\hline Diabetes & 14.3 & 21.1 & 14.5 & $16.5^{* \neq}$ \\
\hline$(\%, 95 \% \mathrm{Cl})$ & (8.5 to 21.9 ) & (18.7 to 23.6$)$ & (13.3 to 15.8$)$ & (15.1 to 18.1$)$ \\
\hline Chronic kidney disease & 21.0 & $31.0^{*}$ & $30.8^{\dagger}$ & $44.2^{* \neq}$ \\
\hline$\left(\%\right.$ eGFR $\left.<60 \mathrm{~mL} / \mathrm{min} / 1.73 \mathrm{~m}^{2}, 95 \% \mathrm{Cl}\right)$ & (14.1 to 29.4$)$ & (28.2 to 33.8 ) & (29.3 to 32.4 ) & (42.2 to 46.2 ) \\
\hline Hypertension & 41.2 & 49.6 & $56.8^{\dagger}$ & $61.1^{\text {* }}$ \\
\hline$(\%, 95 \% \mathrm{Cl})$ & (32.2 to 50.6$)$ & (46.6 to 52.6 ) & (55.1 to 58.5 ) & (59.1 to 63.0$)$ \\
\hline Previous smoking & 44.5 & $54.4^{*}$ & 48.6 & 50.7 \\
\hline$(\%, 95 \% \mathrm{Cl})$ & (35.4 to 53.9 ) & (51.3 to 57.4 ) & (46.9 to 50.4 ) & (48.7 to 52.7 ) \\
\hline Current smoking & 37.5 & 25.9 & $17.3^{\dagger}$ & 19.9 \\
\hline$(\%, 95 \% \mathrm{Cl})$ & (24.9 to 51.5 ) & (22.4 to 29.7) & (15.5 to 19.2 ) & (17.7 to 22.3 ) \\
\hline \multicolumn{5}{|l|}{ Preoperative status } \\
\hline NYHA classes III and IV & 42.9 & $58.4^{*}$ & 38.8 & $53.0^{* \neq}$ \\
\hline$(\%, 95 \% \mathrm{Cl})$ & (33.8 to 52.3 ) & (55.4 to 61.4 ) & (37.2 to 40.5 ) & (51.0 to 55.1 ) \\
\hline Atrial fibrillation & 26.1 & $48.9^{*}$ & 20.7 & $33.6^{* \ddagger}$ \\
\hline$(\%, 95 \% \mathrm{Cl})$ & (18.4 to 34.9 ) & (45.9 to 51.9 ) & (19.3 to 22.1$)$ & (31.7 to 35.6 ) \\
\hline LVEF $>45 \%$ & 79.0 & 85.7 & 79.1 & $75.7^{* \ddagger}$ \\
\hline$(\%, 95 \% \mathrm{Cl})$ & (70.6 to 85.9 ) & (83.5 to 87.7 ) & (77.6 to 80.5 ) & (73.9 to 77.4 ) \\
\hline LVEF $30-45 \%$ & 15.1 & 10.5 & 13.3 & $17.5^{* \ddagger}$ \\
\hline$(\%, 95 \% \mathrm{Cl})$ & (9.2 to 22.8 ) & (8.7 to 12.5 ) & (12.1 to 14.5$)$ & (16.0 to 19.1$)$ \\
\hline LVEF $<30 \%$ & 4.2 & 1.9 & 6.2 & $4.3^{* \neq}$ \\
\hline$(\%, 95 \% \mathrm{Cl})$ & (1.4 to 9.5$)$ & (1.2 to 3.0$)$ & (5.4 to 7.0 ) & (3.5 to 5.1 ) \\
\hline Moderate or severe mitral valve regurgitation & 81.5 & $63.9^{*}$ & $91.4^{\dagger}$ & $86.8^{* \ddagger}$ \\
\hline$(\%, 95 \% \mathrm{Cl})$ & (73.4 to 88.0$)$ & (60.9 to 66.8$)$ & (90.4 to 92.4 ) & (85.4 to 88.2 ) \\
\hline Mitral valve stenosis & 25.2 & $75.3^{*}$ & $8.2^{\dagger}$ & $18.9^{* \ddagger}$ \\
\hline$(\%, 95 \% \mathrm{Cl})$ & (17.7 to 34.0$)$ & (72.6 to 77.8 ) & (7.2 to 9.1$)$ & (17.4 to 20.6) \\
\hline \multicolumn{5}{|l|}{ Previous procedures } \\
\hline Valve surgery & 1.7 & $13.5^{*}$ & 2.2 & $16.4^{* \ddagger}$ \\
\hline$(\%, 95 \% \mathrm{Cl})$ & (0.2 to 5.9$)$ & (11.6 to 15.7$)$ & (1.7 to 2.8 ) & (15.0 to 18.0$)$ \\
\hline Percutaneous balloon valvuloplasty & 7.7 & 28.6 & $0.6^{\dagger}$ & $2.1^{* \neq}$ \\
\hline$(\%, 95 \% \mathrm{Cl})$ & $(0.2$ to 36.0$)$ & (23.4 to 34.1 ) & (0.1 to 1.7$)$ & (1.2 to 3.4$)$ \\
\hline
\end{tabular}

${ }^{*}$ Comparing repair and replacement, $\mathrm{p}<0.05$.

tComparing RHD and non-RHD repair, $p<0.05$.

$\neq$ Comparing RHD and non-RHD replacement, $p<0.05$.

CABG, coronary artery bypass grafting; LVEF, left ventricular ejection fraction; NYHA, New York Hearth Association; RHD, rheumatic heart disease

in ICU and hospital, were less likely to be readmitted for any reason, require further surgery for non-valve related reasons, or have acute kidney injury, stroke or TIA, anticoagulant complications, heart failure or septicaemia.

The only difference in short-term outcome for Indigenous Australians undergoing RHD mitral valve repair was a shorter length of hospital stay (mean 11.9 days, SD 17.7, compared with 9.5 days, SD 10.2, $\mathrm{p}=0.025$ ). There were no reoperations for valve dysfunction reported in this group of patients within 30 days, for those undergoing either mitral repair or replacement.

Unadjusted analysis of 30-day survival demonstrated no difference in RHD mitral valve repair surgery compared with replacement $(95.8 \%$ vs $96.2 \%, p=0.830)$. In contrast, unadjusted
non-RHD mitral valve surgery 30-day survival following repair surgery was superior to that seen with replacement $(96.5 \%$ compared with $92.6 \%, \mathrm{p}<0.001$ ). In addition 30 -day survival following replacement surgery was superior for RHD compared with non-RHD replacement surgery $(p<0.001)$, but was no different for repair $(\mathrm{p}=0.701)$. Short-term survival was comparable for Indigenous Australians requiring RHD mitral valve surgery at $96.7 \%$ and did not differ between repair and replacement $(97.1 \%$ vs $96.6 \%, p=0.861)$.

There remained no significant difference in short-term survival following RHD mitral valve repair versus replacement (relative to replacement) overall (OR $0.5,95 \%$ CI 0.1 to 2.0) and for Indigenous Australians specifically (OR 0.9, 95\% CI 0.1 
Table 2 Outcome following RHD-related mitral valve surgery within 30 days, stratified by aetiology and surgery type

\begin{tabular}{|c|c|c|c|c|}
\hline & \multicolumn{2}{|l|}{ RHD } & \multicolumn{2}{|l|}{ Non-RHD } \\
\hline & $\begin{array}{l}\text { Repair } \\
\text { surgery } n=119\end{array}$ & $\begin{array}{l}\text { Replacement } \\
\text { surgery } n=1078\end{array}$ & $\begin{array}{l}\text { Repair } \\
\text { surgery } n=3279\end{array}$ & $\begin{array}{l}\text { Replacement } \\
\text { surgery } n=2400\end{array}$ \\
\hline \multicolumn{5}{|l|}{ Initial admission } \\
\hline Ventilation (hours) & 11.3 & 13.5 & 8.0 & $10.0^{* \dagger}$ \\
\hline (median IQR) & (6.6 to 21.8$)$ & (8.0 to 21.0$)$ & (6.0 to 12.0$)$ & (7.0 to 17.0$)$ \\
\hline ICU stay & 46.8 & 46.7 & 47.1 & $68.2^{*^{\dagger}}$ \\
\hline (hours) (median, IQR) & (25.8 to 96.0$)$ & (24.0 to 91.6$)$ & (24.7 to 88.5$)$ & (36.6 to 122.8$)$ \\
\hline Post-procedure length of stay & 11.7 & $12.2^{*}$ & 11.4 & $16.7^{\star \dagger}$ \\
\hline (days) (mean, SD) & $(11.8)$ & (13.4) & $(11.8)$ & $(76.6)$ \\
\hline Reoperation for valve dysfunction & 1.7 & $0.3^{*}$ & 0.5 & 0.3 \\
\hline$(\%, 95 \% \mathrm{Cl})$ & (0.2 to 5.9$)$ & (0.06 to 0.8$)$ & (0.3 to 0.8$)$ & (0.1 to 0.7 ) \\
\hline Reoperation not related to valve dysfunction & 7.6 & 7.3 & 6.3 & $10.9^{* \dagger}$ \\
\hline$(\%, 95 \% \mathrm{Cl})$ & (3.5 to 13.9 ) & (5.8 to 9.0$)$ & (5.4 to 7.1$)$ & (9.7 to 12.2$)$ \\
\hline Mortality (all cause) & 4.2 & 3.8 & 3.5 & $7.4^{\star^{\dagger}}$ \\
\hline$(\%, 95 \% \mathrm{Cl})$ & (1.4 to 9.5$)$ & (2.7 to 5.1$)$ & (2.9 to 4.2 ) & (6.4 to 8.5$)$ \\
\hline Readmission & 9.7 & 15.6 & 9.9 & $13.1^{* \dagger}$ \\
\hline$(\%, 95 \% \mathrm{Cl})$ & (5.0 to 16.8 ) & (13.5 to 18.0$)$ & (8.9 to 11.0$)$ & (11.7 to 14.5$)$ \\
\hline \multicolumn{5}{|l|}{ Other complications } \\
\hline Readmission for valve dysfunction & 0 & 0 & 0.6 & 0.6 \\
\hline$(\%, 95 \% \mathrm{Cl})$ & & & (0.3 to 1.3 ) & (0.2 to 1.3$)$ \\
\hline Acute kidney injury & 4.3 & 6.7 & 5.4 & $9.7^{\star \dagger}$ \\
\hline$(\%, 95 \% \mathrm{Cl})$ & (1.4 to 9.7 ) & (5.3 to 8.4 ) & (4.6 to 6.2 ) & (8.6 to 11.0$)$ \\
\hline New AF & 15.1 & 17.2 & 24.3 & 23.4 \\
\hline (\% without prior $\mathrm{AF}, 95 \% \mathrm{Cl}$ ) & (15.0 to 19.5$)$ & (9.2 to 22.8 ) & (22.8 to 25.8 ) & (21.7 to 25.1 ) \\
\hline Stroke/TIA & 1.7 & 1.7 & 2.1 & $3.8^{*^{\dagger}}$ \\
\hline$(\%, 95 \% \mathrm{Cl})$ & (0.2 to 5.9$)$ & (1.0 to 2.6$)$ & (1.6 to 2.7$)$ & (3.0 to 4.6 ) \\
\hline Deep sternal wound infection & 0.8 & 1.5 & 0.8 & 0.8 \\
\hline$(\%, 95 \% \mathrm{Cl})$ & (0.0 to 4.6$)$ & (0.9 to 2.4 ) & (0.5 to 1.2$)$ & (0.5 to 1.3 ) \\
\hline Anticoagulant complication (bleeding or embolisation) & 4.2 & 2.7 & $1.6^{\ddagger}$ & $3.1^{*}$ \\
\hline$(\%, 95 \% \mathrm{Cl})$ & (1.4 to 9.5$)$ & (1.8 to 3.8$)$ & (1.1 to 1.9$)$ & (2.5 to 3.9$)$ \\
\hline Heart failure & 1.7 & 3.4 & 0.9 & $3.8^{*}$ \\
\hline$(\%, 95 \% \mathrm{Cl})$ & (0.0 to 9.1$)$ & (2.0 to 5.5$)$ & (0.4 to 1.7$)$ & (2.6 to 5.3 ) \\
\hline Septicaemia (positive blood culture with signs of infection) & 1.7 & 1.5 & 1.4 & $3.1^{* \dagger}$ \\
\hline$(\%, 95 \% \mathrm{Cl})$ & $(0.2$ to 6.0$)$ & (0.9 to 2.4$)$ & (1.1 to 1.9$)$ & (2.5 to 3.9$)$ \\
\hline
\end{tabular}

${ }^{*}$ Comparing repair and replacement, $\mathrm{p}<0.05$.

tComparing RHD and non-RHD replacement, $\mathrm{p}<0.05$.

$\ddagger$ Comparing RHD and non-RHD repair, $p<0.05$.

$A F$, atrial fibrillation; ICU, intensive care unit; RHD, rhuematic heart disease; TIA, transient ischaemic attack.

to 11.5$)$ after controlling for previously identified covariates (LVEF $<30 \%$, a longer period of ventilation, and a shorter initial stay in hospital) in logistic regression modelling. ${ }^{13}$

The superior unadjusted short-term survival seen with non-RHD mitral valve repair did not persist after controlling for other previously identified factors (chronic kidney disease, previous valve surgery, prolonged stay in ICU, reoperation, acute kidney injury, septicaemia) associated with 30-day survival (OR $1.1,95 \%$ CI 0.6 to 2.0$){ }^{12}$

\section{Long-term survival}

Survival to 5 years following RHD-related mitral valve surgery was $84.0 \%$ (95\% CI $80.2 \%$ to $87.3 \%$ ), with mitral valve repair $82.4 \%$ (95\% CI $69.1 \%$ to $91.6 \%$ ) and replacement $84.2 \%$ (95\% CI $80.2 \%$ to $87.7 \%$ ). For non-RHD mitral valve surgery, survival to 5 years was $83.6 \%$ (95\% CI $81.7 \%$ to $85.3 \%$ ) overall, with repair $86.7 \%$ (95\% CI $84.4 \%$ to $88.7 \%$ ) and replacement $79.5 \%$ (95\% CI 76.4\% to 82.4\%). For Indigenous Australians, survival to 5 years following RHD-related mitral valve surgery was comparable with $83.3 \%$ (95\% CI 69.8\% to $92.5 \%$ ) overall, repair $85.0 \%$ (95\% CI $62.1 \%$ to $96.8 \%)$ and replacement $82.1 \%$ (95\% CI $63.1 \%$ to $93.9 \%$ ).

Kaplan-Meier curves comparing survival in RHD and non-RHD mitral valve repair and replacement valve surgery are shown in figures 2 and 3. Log rank testing demonstrated no difference in unadjusted survival between RHD-related mitral valve repair and replacement (HR $0.86,95 \%$ CI 0.4 to 1.7 ) or in Indigenous Australians with RHD specifically. For non-RHD mitral valve surgery, survival following repair was superior to replacement (HR 1.7, 95\% CI 1.4 to 2.0), RHD and non-RHD repair no different (HR $0.9,95 \%$ CI 0.5 to 1.7 ) and survival following RHD-related mitral valve replacement was superior to that seen with non-RHD replacement (HR 1.5, 95\% CI 1.2 to 1.9 ).

When other factors associated with long-term survival were controlled for in Cox proportional modelling (age, diabetes, chronic kidney disease, prolonged ventilation time and prolonged post-procedural length of hospital stay), ${ }^{12} 1316$ there remained no significant difference in survival between repair 

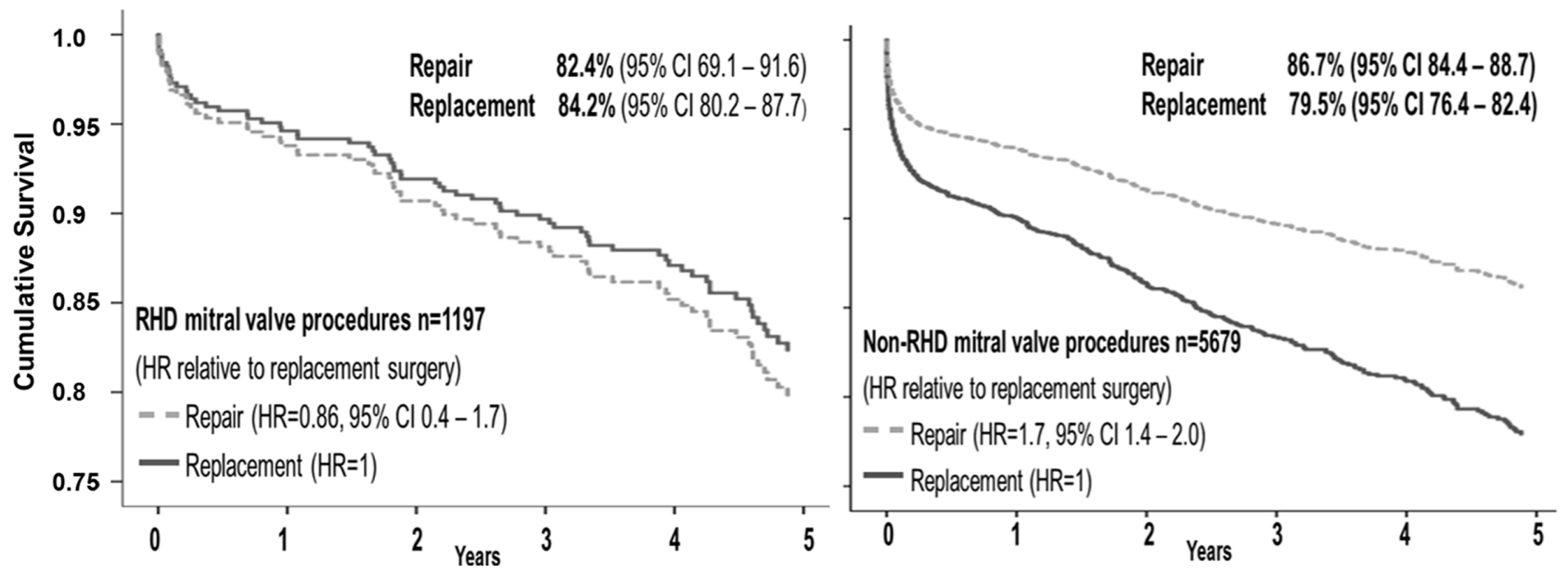

Figure 2 Cumulative survival following rheumatic heart disease (RHD) and non-RHD related mitral valve procedures.

and replacement following RHD-related surgery (HR 0.7, 95\% CI 0.4 to 1.6 ), and the differences seen in unadjusted non-RHD repair and replacement (HR 1.4, 95\% CI 0.9 to 2.0) were no longer present.

In addition, there remained no difference in survival on Cox proportional modelling between RHD and non-RHD mitral valve repair patients (HR 1.3, 95\% CI 0.2 to 10.4), and the unadjusted differences seen in mitral valve replacement in RHD and non-RHD patients (HR 1.3, 95\% CI 0.8 to 2.1) were no longer present.

\section{DISCUSSION}

In this large Australian cohort study we have demonstrated that for RHD-related mitral valve disease both short-term and longer-term unadjusted and adjusted survival for valve repair and replacement are no different. While non-RHD related mitral valve disease repair is associated with superior unadjusted survival this is also no different once controlling for covariates.

Patients undergoing mitral repair surgery, either RHD or non-RHD, were younger and predominantly male. For RHD-related mitral repair surgery, patients were more likely to be Indigenous Australian. With specific reference to RHD-related mitral valve disease this would suggest young male patients were referred either at a sufficiently early phase of their disease, when their valve was more amenable to surgical repair, and/or were referred to a surgical centre with a greater interest and capacity to undertake mitral valve repair. This would appear to favour a reduced need for postoperative anticoagulation in younger men, giving them options for physical occupations and contact sport unavailable after a mechanical valve replacement with attendant long-term anticoagulation. Nonetheless, a male predominance would also highlight that young women, in whom the issue of anticoagulation and pregnancy can be a particular issue, may have been relatively overlooked. This may in part be related to a preference in this group to instead use a bioprosthetic mitral valve replacement to obviate the need for ongoing anticoagulation.

RHD-related mitral valve repair surgery was also significantly more common in patients with moderate or severe mitral valve regurgitation rather than stenosis. Given mitral stenosis is likely to reflect more advanced RHD-related mitral valve disease, such an association would highlight the importance of early referral for assessment for suitability for repair. In this case it could be argued that optimising the opportunity for successful mitral repair may require surgery at a time that would be earlier than that which may be required for replacement.

The broader issue of making management recommendations for RHD-related mitral valve disease based on evidence gleaned from the management of non-RHD valve disease, and particularly myxomatous degeneration, is also important. Our findings highlight that such generalisation should be undertaken cautiously given differing pathologic processes and the greater role of fibrosis and calcification in RHD mitral valve disease that can involve both valve leaflets and chordae tendonae. ${ }^{18}$

Whether the possibility of successful mitral valve repair increases with site and surgeon experience remains debatable. Some studies investigating case load and mitral valve repair have specifically suggested the development of centres of
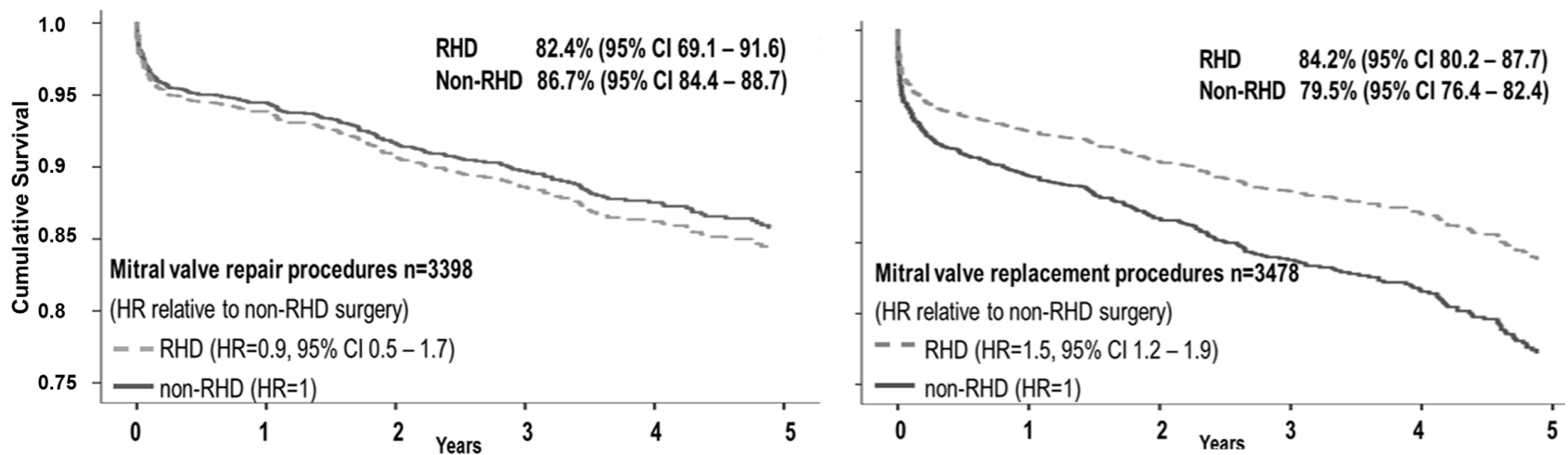

Figure 3 Cumulative survival following mitral valve repair and replacement procedures. RHD, rheumatic heart disease. 
excellence for mitral valve repair, ${ }^{19-22}$ with minimum standards suggested for such centres. ${ }^{23}$ This is supported by our earlier Australian study where we found RHD mitral valve repair was more common in higher volume centres $(\mathrm{p}<0.001$ for increasing site case load strata) and for higher volume surgeons ( $p=0.001$ for increasing surgeon case load group). ${ }^{16}$ Nonetheless it should be highlighted that this did not in turn confer improved long-term outcome.

Mitral valve repair was less common in patients with concomitant preoperative comorbidities, including New York Heart Association (NYHA) functional classes III and IV, chronic kidney disease and atrial fibrillation (AF), which have all previously been found to be predictors of subsequent mortality following RHD mitral valve surgery. ${ }^{24-29}$ This is consistent with these patients having more advanced mitral RHD which are therefore less amenable to repair. The prevalence of preoperative AF is particularly high in patients with valvular disease due to RHD, ${ }^{12}$ with its occurrence most common in mitral stenosis. ${ }^{30}$ Undertaking RHD mitral valve surgery before the onset of AF could provide greater therapeutic choice and optimise the opportunity for repair being undertaken.

We found no difference in adjusted short- or long-term survival following RHD mitral valve repair surgery, compared with replacement. Our level of survival and this lack of difference between surgical type was in line with many earlier studies of mitral valve repair and replacement for RHD related ${ }^{3132}$ and non-RHD related valve disease. ${ }^{33-35}$ Such findings have not been seen in all studies with repair particularly associated with superior survival in younger patients. ${ }^{36-38}$ Remenyi et al's New Zealand and Pacific island study ${ }^{36}$ reported survival at 10 and 14 years following mitral valve surgery to be $79 \%$ and $44 \%$ for replacement compared with $90 \%$ and $90 \%$ for repair. While half of these patients were from remote Pacific island nations (where the outcome of mitral valve replacement might be anticipated to be poorer), when analysis was restricted to New Zealand residents, this difference, while less, persisted.

\section{LIMITATIONS}

The main limitation of this study is that it is restricted to Australian surgical practice and may not reflect management in other countries. Nonetheless, overall this sample is likely to provide an accurate representation of surgical management of valve disease in Australia that is referable to practice in other high income countries. Multiple data collection sites and personnel may have led to variable data coding. This was, however, minimised by each site being supported with training and standard data definitions, the use of standardised data entry systems, and centralised auditing of site-specific data. The data were from the Australia and New Zealand Society of Cardiac and Thoracic Surgeons (ANZSCTS) National Cardiac Surgery Database, an Australia-wide voluntary registry for the prospective collection and analysis of the results of cardiac surgery. The database does not currently collect all known risk factors or quality-of-life data and these could not be included for analysis. While our overall numbers were high, subgroup and multivariate analysis may also have potentially reduced our power to identify differences in outcomes. Long-term outcome was only possible for 5 years which may not reflect the need for late reoperation with its associated morbidity and mortality, especially in the mitral valve repair group. Finally longer-term morbidity including heart failure, endocarditis, bleeding and cardioembolic complications have not been investigated.

\section{CONCLUSION}

In this large prospective cohort study we have demonstrated survival following RHD mitral valve repair surgery in Australia is no different to replacement surgery in line with some, ${ }^{31}{ }^{32}$ but not all, earlier studies. ${ }^{829}$ While unadjusted survival for non-RHD valve repair out to 5 years appeared superior to replacement, this did not persist when adjusting for other factors associated with early mortality. This study highlights the importance of adjusting for patient factors when assessing the outcome of valve surgery and the benefit of determining surgical choice based on a combination of valve disease aetiology, valve morphology and patient demographics and comorbidities. Whether mitral repair compared with replacement is associated with a difference in non-lethal complications, including long-term morbidity, healthcare utilisation and cost should remain a priority for future research.

Correction notice This paper has been amended since it was published Online First. Owing to a scripting error, some of the publisher names in the references were replaced with 'BMJ Publishing Group'. This only affected the full text version, not the PDF. We have since corrected these errors and the correct publishers have been inserted into the references.

Acknowledgements Submitted on behalf of the investigators, data managers and institutions participating in the ANZSCTS Database. Anne Russell is supported by an NHMRC Postgraduate Scholarship. Graeme Maguire is supported by an NHMRC Practitioner Fellowship. Christopher Reid is supported by an NHMRC Senior Research Fellowship. Alex Brown is supported by a Viertel Senior Medical Research Fellowship. Supported by NHMRC Centres for Research Excellence to Reduce Inequality in Heart Disease (NHMRC Grant ID: 1044897) and END RHD (NHMRC Grant ID: 1080401) and the Victorian Government's OIS Programme. The Australian and New Zealand Society of Cardiac and Thoracic Surgeons (ANZSCTS) National Cardiac Surgery Database Programme is funded by the Department of Health Victoria, the Health Administration Corporation (GMCT) and the Clinical Excellence Commission (CEC) NSW, and funding from individual Units.

Contributors EAR performed the statistical analysis and drafted the manuscript. LT assisted with acquisition of data and analysis. RAB, JSB, AB and RT helped with revision of the manuscript. CMR assisted with acquisition of data and helped with

\section{Key messages}

What is already known about this subject?

Previous international studies, while identifying factors that may influence the type of surgical management for RHD related valve disease, have provided limited evidence to indicate the most appropriate timing and choice of intervention. Many previous international studies concluded RHD related mitral valve repair was associated with superior overall short- and intermediateterm outcomes but with an increased need for early reoperation.

\section{What does this study add?}

This study demonstrateds that in a high-income country such as Australia, adjusted long-term survival following valve repair in comparison with valve- replacement for RHD and non-RHD related mitral valve disease is no different.

How might this impact on clinical practice? In high-income countries such as Australia the evaluation of long-term survival following mitral valve surgery, irrespective of cause, should take account of patient factors beyond surgical choice alone. The lack of any difference in outcome is likely to reflect a combination of patient environmental factors and access to ongoing primary and specialist care following surgery. 
revision of the manuscript. WW conceived of the study and participated in its design and coordination and helped with revision of the manuscript. GPM conceived of the study, participated in the design of the study, assisted with the statistical analysis and interpretation, and helped to draft the manuscript. All authors read and approved the final manuscript.

\section{Competing interests None declared.}

Patient consent Opt-out consent was given at the time of surgery for data collection for a national database with the explanation that the data were to collate the activities and outcomes of participating units and give an overview of the patients who underwent surgery, the types of surgery performed, complications and other details relating to risk and the outcomes of cardiac surgery. This de-identified database was used for this research.

Ethics approval Monash University.

Provenance and peer review Not commissioned; externally peer reviewed.

Data sharing statement The data were from Australia and New Zealand Society of Cardiac and Thoracic Surgeons (ANZSCTS) National Cardiac Surgery Database, an Australia-wide voluntary registry for the prospective collection and analysis of the results of cardiac surgery. Access to this data is via written application to the administrators at Monash University, Melbourne Australia with ethical approval.

(c) Article author(s) (or their employer(s) unless otherwise stated in the text of the article) 2017. All rights reserved. No commercial use is permitted unless otherwise expressly granted.

\section{REFERENCES}

1 Maguire GP, Carapetis JR, Walsh WF, et al. The future of acute rheumatic fever and rheumatic heart disease in Australia. Med J Aust 2012;197:133-4.

2 The Joint Task Force on the management of valvular heart disease of the European Society of Cardiology (ESC) and the European Association for Cardio-Thoracic Surgery (EACTS). Guidelines on the management of valvular heart disease (version 2012). Eur Heart J 2012;33:2451-96.

3 RHDAustralia (ARF/RHD writing group) National Heart Foundation of Australia and the Cardiac Society of Australia and New Zealand. Australian guideline for prevention diagnosis and management of acute rheumatic fever and rheumatic heart disease. Darwin, NT Australia: Menzies School of Health Research, 2012.

4 Essop MR, Nkomo VT. Rheumatic and nonrheumatic valvular heart disease: epidemiology, management, and prevention in Africa. Circulation 2005;112:3584-91.

5 Borer JS, Bonow RO. Contemporary approach to aortic and mitral regurgitation. Circulation 2003:108:2432-8

6 Carapetis J, Fever R, et al. In: Cohen J, Powderly W, Berkley S, eds. Robbins and Cotran Pathologic Basis of Disease, Professional Edition. 1 . 8th ed. Philadelphia: PA: Saunders Elsevier, 2010

7 Couzos S, Carapetis J, Fever R. In: Couzo M, Murray R, eds. Aboriginal Primary Health Care: an Evidence-Based approach. 2nd ed. Melbourne: Oxford University Press, 2003

8 Yau TM, El-Ghoneimi YA, Armstrong S, et al. Mitral valve repair and replacement for rheumatic disease. I Thorac Cardiovasc Surg 2000;119:53-61.

9 White $\mathrm{H}$, Walsh W, Brown $\mathrm{A}$, et al. Rheumatic heart disease in indigenous populations. Heart Lung Circ 2010;19(5-6):273-81.

10 Bakir I, Onan B, Onan IS, et al. Is rheumatic mitral valve repair still a feasible alternative?: indications, technique, and results. Tex Heart / / 2013;40:163-9.

11 Kumar AS, Rao PN, Saxena A. Results of mitral valve reconstruction in children with rheumatic heart disease. Ann Thorac Surg 1995;60:1044-7.

12 Russell EA, Tran L, Baker RA, et al. A review of valve surgery for rheumatic heart disease in Australia. BMC Cardiovasc Disord 2014:14:134

13 Russell EA, Tran L, Baker RA, et al. A review of outcome following valve surgery for rheumatic heart disease in Australia. BMC Cardiovasc Disord 2015:15:103.
14 Australian and New Zealand Society of Cardiac and Thoracic Surgeons (ANZSCTS). Monash University, 2010. https://anzscts.org/national-database// Melbourne: CCRE. (accessed 11 Aug 2016).

15 ANZSCTS. National Cardiac Surgery Database Program, Standard Operating Procedures Manual v1.1. Melbourne: CCRE, Monash University, 2012.

16 Russell EA, Baker RA, Bennetts IS, et al. Case load and valve surgery outcome in Australia. Int J Cardiol 2016;221:144-51.

17 von Elm E, Altman DG, Egger M, et al. The Strengthening the Reporting of Observational Studies in Epidemiology (STROBE) statement: guidelines for reporting observational studies. J Clin Epidemiol 2008;61:344-9.

18 Rajamannan NM. Myxomatous mitral valve disease bench to bedside: LDL-densitypressure regulates Lrp5. Expert Rev Cardiovasc Ther 2014;12:383-92.

19 Suri RM, Clavel M-A, Schaff HV, et al. Effect of recurrent mitral regurgitation following degenerative mitral valve Repair. J Am Coll Cardiol 2016;67:488-98.

20 Bolling SF, Li S, O'Brien SM, et al. Predictors of mitral valve repair: clinical and surgeon factors. Ann Thorac Surg 2010;90:1904-12.

21 LaPar DJ, Ailawadi G, Isbell JM, et al. Mitral valve repair rates correlate with surgeon and institutional experience. I Thorac Cardiovasc Surg 2014;148:995-1004.

22 Castillo JG, Anyanwu AC, Fuster V, et al. A near 100\% repair rate for mitral valve prolapse is achievable in a reference center: implications for future guidelines. $J$ Thorac Cardiovasc Surg 2012;144:308-12.

23 Bridgewater B, Hooper T, Munsch C, et al. Mitral repair best practice: proposed standards. Heart 2006;92:939-44.

24 Wisenbaugh T, Skudicky D, Sareli P. Prediction of outcome after valve replacement for rheumatic mitral regurgitation in the era of chordal preservation. Circulation 1994:89:191-7.

25 Talwar S, Rajesh MR, Subramanian A, et al. Mitral valve repair in children with rheumatic heart disease. J Thorac Cardiovasc Surg 2005;129:875-9.

26 Choudhary SK, Talwar S, Dubey B, et al. Mitral valve repair in a predominantly rheumatic population: long-term results. Tex Heart / J 2001;28:8-15.

27 Skoularigis J, Sinovich V, Joubert G, et al. Evaluation of the long-term results of mitral valve repair in 254 young patients with rheumatic mitral regurgitation. Circulation 1994:90(5 Pt 2):|I167-||174.

28 Lehman SJ, Baker RA, Aylward PE, et al. Outcomes of cardiac surgery in indigenous Australians. Med J Aust 2009:190:588-93.

29 Enriquez-Sarano M, Tajik AJ, Schaff HV, et al. Echocardiographic prediction of survival after surgical correction of organic mitral regurgitation. Circulation 1994;90:830-7.

30 Diker E, Aydogdu S, Ozdemir M, et al. Prevalence and predictors of atrial fibrillation in rheumatic valvular heart disease. Am I Cardio/ 1996;77:96-8.

$31 \mathrm{Kim} \mathrm{JB}, \mathrm{Kim} \mathrm{HJ}$, Moon DH, et al. Long-term outcomes after surgery for rheumatic mitral valve disease: valve repair versus mechanical valve replacement. Eur $J$ Cardiothorac Surg 2010;37:1039-46.

32 Wang YC, Tsai FC, Chu JJ, et al. Midterm outcomes of rheumatic mitral repair versus replacement. Int Heart J 2008;49:565-76, http://doi.org/.

33 Acker MA, Parides MK, Perrault LP, et al. Mitral-valve repair versus replacement for severe ischemic mitral regurgitation. N Engl J Med 2014;370:23-32.

34 Moss RR, Humphries KH, Gao M, et al. Outcome of mitral valve repair or replacement: a comparison by propensity score analysis. Circulation 2003;108::9011-7.

35 Mohty D, Orszulak TA, Schaff HV, et al. Very long-term survival and durability of mitral valve repair for mitral valve prolapse. Circulation 2001;104(12 Suppl 1):1-7.

36 Remenyi B, Webb R, Gentles T, et al. Improved long-term survival for rheumatic mitral valve repair compared to replacement in the young. World I Pediatr Congenit Heart Surg 2013;4:155-64.

37 De Santo LS, Romano G, Della Corte A, et al. Mitral mechanical replacement in young rheumatic women: analysis of long-term survival, valve-related complications, and pregnancy outcomes over a 3707-patient-year follow-up. J Thorac Cardiovasc Surg 2005:130:13-19.

38 Wang Z, Zhou C, Gu H, et al. Mitral valve repair versus replacement in patients with rheumatic heart disease. J Heart Valve Dis 2013;22:333-9. 